\title{
¿La teología monástica es extemporánea? Formulación desde El quehacer de la teología de Olegario González de Cardedal
}

\author{
Pedro Edmundo Gómez, os ${ }^{1}$ \\ ABADÍA CRISTO REY \\ TUCUMÁN
}

A lo largo de la lectura de El quehacer de la teología de Olegario González de Cardedal ${ }^{2}$, que es la vez una fundamentación y una invitación al estudio exponiendo descriptivamente la génesis, ejercicio, técnica y alma de la teología a lo largo de la historia, nos hemos encontrado con repetidas referencias a un tema que nos interesa particularmente: la teología monástica ${ }^{3}$. Esto no habla solo de que existieron en el pasado diversas formas de ser teólogo y por ende de hacer teología, sino que plantea una cuestión: ¿La teología monástica es, con respecto a nuestro propio tiempo histórico, extemporánea? La misma no carece de importancia y urgencia, como veremos, no solo para los monjes. Dice el teólogo español: «Hay autores que son extemporáneos respecto de su tiempo, unos porque resultan arcaicos, es decir reflejan una fase de la conciencia humana ya agotada o superada, otros, en cambio son extemporáneos, porque hablan desde un horizonte y percepción nueva del cristianismo para los cuales todavía no hay ojos ni oídos» ${ }^{4}$.

\footnotetext{
Monje del Monasterio Nuestra Señora de la Paz, San Agustín, Córdoba, Argentina.

2 Este teólogo es miembro de la Sociedad Española de Estudios Monásticos.

3 Cf. P. E. Gómez, «Algunas consideraciones sobre la Teología Monástica de los siglos XI y XII, en Res-Vista II, 2 (2000), 13-32; «Algunas cuestiones epistemológicas a propósito de la teología monástica medieval en Jean Leclercq", en Teología y Vida XLVII, 4 (2006), 479-496.

4 O. González de Cardedal, El quehacer de la teologia, Génesis, Estructura y Misión (Sígueme, Salamanca 2008), 649. Los primeros son propiamente extemporáneos y los segundos postemporáneos.
} 
Teniendo en cuenta la presencia en diez oportunidades de la palabra y/o de la idea de "teología monástica» ${ }^{5}$ y de más de dieciocho referencias a sus dos figuras más importantes: Anselmo y Bernardo ${ }^{6}$, nuestro intento de respuesta a la pregunta nos llevará a abordar sintéticamente los principales núcleos conceptuales de la obra. Seguiremos el orden de los capítulos, cuando las referencias sean explícitas transcribiremos el texto y lo contextualizaremos, y en los que la temática esté ausente, intentaremos proponerla por nuestra propia cuenta y riesgo.

I

La primera aparición de la denominación se da cuando a la vez presenta a los más reconocidos representantes y define genéricamente esta particular forma de hacer teología: «San Bernardo (1090-1153) y san Anselmo (1033-1109) fueron dos exponentes de la "teología monástica", que ordena la reflexión ante todo y principalmente a la divina alabanza y al amor de Dios» ${ }^{7}$. En la nota que coloca a pie de página encontramos la obligada referencia a J. Leclercq, M-D. Chenu y Ph. Nouzille, quienes formularon esta noción y la lanzaron al debate teológico contemporáneo, este será el marco teórico de su abordaje.

El texto se encuentra en el primer capítulo «La palabra y la idea» donde por el camino de la etimología se propone un primer acercamiento a la teología, a partir de la riqueza que encierra su genitivo: sobre, hacia, ante, desde o de Dios.

Si bien se trata de un término surgido en el mundo griego en tres contextos distintos: en relación con el culto y la poesía, como proclamación hímnica de Dios; con el mito y la metafísica, en cuanto crítica que la razón filosófica ejerce rechazando la comprensión antropomórfica; y con la física y la matemática, en tanto saber especulativo sobre la causa primera, estas determinaciones perdurarán a lo largo de la historia hasta nuestros días.

5 No todas las referencias aparecen en el índice temático de la obra.

6 Dejamos de lado las referidas de paso a otros teólogos como por ejemplo Beda (p. 415) y Hildegarda de Bingen (p. 362), igualmente las relacionadas con monjes teólogos que se dedicaron a un área específica del saber teológico como L. Beauduin, O. Casel o G. Lafont.

7 O. González de Cardedal, El quehacer de la teología..., 29. 
La palabra fue asumida (continuidad) en un nuevo contexto (transformación innovadora de la experiencia salvífica) no en la Escritura sino por la Tradición y enriquecida (ruptura) con nuevos y diversos sentidos en la Patrística y en la Edad Media, cuando el kérygma cristiano entra en diálogo con el logos, dando origen a un saber distinto a la palabra desde Dios de los profetas judíos y a la palabra abstracta sobre Dios de los filósofos griegos. Uno de esos nuevos significados es el que adquiere durante el Medievo en los monasterios. En la "teología monástica» encontramos reunidas a la luz de la cuarta determinación (Biblia) las dos primeras: liturgia y filosofía, culto y razón. En el desarrollo posterior primará la tercera determinación con sus consecuentes problemas.

Cuando el autor propone algunas definiciones provisionales de teología y considera la propuesta del teólogo suizo H. U. von Balthasar al distinguir el contenido teológico, el aspecto formal, y los estilos, aparece una alusión a san Anselmo como uno de los grandes teólogos representantes del estilo eclesiástico ${ }^{8}$.

En el segundo acápite «El sentido y la misión de la teología» que busca explicitar la apertura metafísica del hombre a Dios y exponer a la vez la entrega histórica de Dios al hombre en Cristo, mostrando la convergencia entre ambas, otro autor monástico aparece ahora para mostrar la novedad de la perspectiva bíblica en la inversión del planteamiento: ya no es el hombre quien primero pregunta por Dios, a partir del mundo, la historia y sí mismo (homo capax Dei), sino Dios quien pregunta al hombre, para que este comprenda y se comprenda (Deus capax hominis), en cita: «El haber sido encontrados suscita en nosotros el deseo de buscarle. Desde san Bernardo, Tomás de Kemptem y Pascal la frase es clásica: "Tú no me buscarías si ya no me hubieras encontrado"...»". Estamos ante la paradoja de que el encuentro (deseo) es el que origina la búsqueda. La revelación suscita la fe y esta exige la búsqueda. Teólogo es quien se atreve a asumir e interpretar la palabra concreta de Cristo.

La teología surge del encuentro de dos culturas: la judía y la griega, pero ¿qué ocurre en el encuentro con la cultura posmoderna? En esta perspectiva, aunque el autor no lo desarrolla, la teología monástica continúa aportando armas contra «Los asedios a la teología cristiana»: frente

8 O. González de Cardedal, El quehacer de la teología..., 33.

9 O. González de Cardedal, El quehacer de la teología..., 37. 
al positivismo científico, mostrando que existe una dimensión espiritual en el hombre y que por ende es posible otro ejercicio de la racionalidad; ante la comprensión racionalista de la experiencia religiosa, poniendo de manifiesto la dimensión religiosa como apertura a una trascendencia; contra la reducción de la positividad cristiana, señalando la existencia objetiva de una historia de la revelación con la fe correspondiente y no solo una historia del sentimiento religioso de la humanidad; y como respuesta al confinamiento mundano de la persona en la cultura del pensamiento débil apostando a una original forma de existencia.

$\mathrm{Al}$ abordar «Los fundamentos de la teología cristiana» (revelación, fe, Iglesia y dogma) y al mostrar cómo la teología redescubrió en el siglo pasado su fundamento dejando en claro a la vez su diferencia específica y su legitimidad histórica, afirma: «En un sentido Barth y en otro Guardini son los exponentes de este retorno a la raíz fundadora de la teología. Uno y otro realizaron esa tarea en sendos libros sobre san Anselmo y su comprensión de la teología como "fides quaerens intellectum -intellectus quaerens fidem"... ${ }^{10}$.

Barth en el lado protestante, como respuesta al liberalismo, y Guardini en el católico, al modernismo, redescubrieron en el siglo XX gracias a un teólogo monástico que la revelación positiva en la historia es el hecho fundante de su quehacer, que posibilita el segundo fundamento: la fe personal. La revelación se da y la fe se vive en la Iglesia, lo que nos lleva al último fundamento: la interpretación autorizada, el dogma. Estos cuatro fundamentos encuentran una síntesis plenamente realizada en los grandes teólogos que han sido grandes santos, hombres de fe, de oración, de Iglesia y de conocimiento-asimilación crítica de las culturas circundantes, dando una nueva expresión al cristianismo. En la lista de estos grandes no podía faltar por supuesto el mismo Anselmo, porque "todos ellos forman el coro sinfónico de la communio theologorum, que en la mayoría de los casos es también communio sanctorum» ${ }^{11}$. La teología monástica es el testimonio de que es posible la síntesis entre: fe, vida y razón, teología y santidad.

En "Gloria y paradojas de la teología» no aparecen alusiones a la teología monástica ni a sus figuras más representativas, pero al hablar de

10 O. González de Cardedal, El quehacer de la teología..., 58.

11 O. González de Cardedal, El quehacer de la teología..., 66. 
la teología como ciencia y sabiduría, es imposible no referir la segunda caracterización a nuestra temática. Lo mismo ocurre al plantear la relación entre teología, oración (personal y litúrgica) y experiencia espiritual. Además si no se quiere reducir la teología a cultura, la referencia a la persona (divina-humana) y al prójimo creyente es inevitable, como lo fue en la teología hecha en los monasterios.

Si el ideal del teólogo es hablar con el rigor y la objetividad del científico y la serenada pasión del místico, su gloria es tener que hablar de Dios y su miseria es no poder hacerlo demostrativamente, y si siguen siendo tres las dimensiones de toda teología: técnica, sapiencial y profética, la teología monástica es aún paradigmática, no exclusivamente en lo que se refiere a la segunda dimensión. Aquí también nos encontramos con otra idea clave: filosofía $=$ forma de vida $=$ monacato $^{12}$, en este punto es deudor de Balthasar y P. Hadot.

Al hablar de la "Unidad y diversidad de la teología» señala que la pluralidad radica en la dedicación a uno u otro aspecto, pero que para permanecer católica cada dimensión debe saberse determinada y completada por la otras. De ahí que el teólogo sea siempre contemporáneo de sus predecesores, que dejan de ser extemporáneos, aquí reside una pista para responder a nuestra problemática. La diversidad pues se explica por la diversidad de contextos donde el teólogo realiza su quehacer, por la pluralidad de filosofías que asume como mediación, por los temas que busca resaltar, las necesidades a las que busca responder y por el carisma personal.

La teología tiene acentos diversos según el lugar concreto en que ella se elabora, y es aquí donde nuestro tema adquiere su primer desarrollo: "Ha habido una teología monástica, elaborada en el monasterio con el templo y la celebración en su centro, destinada a profundizar, explicitar y amar la fe. San Anselmo es el supremo ejemplo y su fecundidad en otro orden se descubre si pensamos que uno de los máximos temas de la filosofía -el "argumento ontológico"- ha nacido de una meditación del abad para sus monjes... teología litúrgico-contemplativa»" ${ }^{13}$. Además hay una teología académica, surgida en las universidades, y una teología

12 Cf. O. González de Cardedal, El quehacer de la teología..., 79.

13 O. González de Cardedal, El quehacer de la teología..., 81-82. 
política, gestada por las calles y plazas. Sobre este punto retornará en varias ocasiones.

Pero en realidad no son tres teologías distintas sino tres formas o acentuaciones de algo que toda teología tiene que hacer aún hoy en su quehacer: nutrirse de las realidades cristianas santificantes (monástica); afirmarse y legitimarse con la racionalidad crítica (académica), y proponerse y acreditarse como una palabra de verdad, libertad y vida en la plaza pública (política).

II

Llegamos al segundo capítulo: «La teología desde la apertura teologal del hombre» que se abre con tres, citas una de Platón, otra de Agustín y la tercera de Guillermo de San Teodorico en la Epistula ad Frates de Monte Dei 259 que dice: «Et haec est forum perfectio, similitudo Dei. Propter hoc enim solum et creati sumus et vivimos, ut deo similes sumus. Ad Dei imaginem enim creati simus». («Toda la perfección de los santos consiste en la semejanza con Dios... Porque hemos sido creados y vivimos exclusivamente para ser semejantes a Dios, ya que fuimos creados a imagen de Dios») ${ }^{14}$.

Hay un doble "desde dónde de la teología»: uno es la constitución teologal del hombre; y el otro, la encarnación de Dios siendo hombre en una historia de autorrevelación y autodonación. Este doble punto de partida se desarrolla en dos momentos: el hombre en su apertura desiderativa, ascendente hacia Dios; y Dios en su apertura encarnativa, descendente, hasta el hombre. La primera sería una «teología filosófica» (pregunta del hombre por Dios) que comienza con el hombre y la naturaleza siendo una forma inicial pero incompleta de la teología fundamental; y la segunda una "teología bíblica» (pregunta de Dios al hombre) que empieza con Dios y la historia. La «teología sistemática» o dogmática sería entonces el discurso que sintetiza preguntas y respuestas en una totalidad orgánica y jerárquica.

La teología deberá entonces esclarecer los puntos de entronque (conexión o preparación) entre la revelación de Dios por medio de la palabra en la historia (revelación, gracia y teología) y los dinamismos intelectivos y volitivos del hombre en su naturaleza específica (presupuestos

14 Guillermo de Saint-Thierry, Carta de Oro y Oraciones meditadas (Monte Carmelo, Burgos 2003), 135. 
ontológicos, antropológicos y existenciales y formas concretas de apertura al misterio, vivencia histórica y metafísica: admiración, interrogación, inquietud y religación), para ver en qué sentido aquella explicita y enriquece, corrige y completa lo que ya estaba germinalmente presente y oscuramente percibido en el corazón del hombre. Así la teología fundamental se vuelve una legitimación permanente de la fe. Sin revelación no hay fe y sin fe la revelación no llega a su destinatario realizando el designio divino, es decir no hay revelación. La fe se presenta así como resultado de la espera humana fundamental (precomprensión humana) confrontada con la revelación, percibida como la consumación de la humanidad, no como su corrección. Una teología sin antropología carece de significación histórica y una antropología sin teología carece de último resuello. Así se cierra el arco abierto por la cita de Guillermo.

\section{III}

«La teología desde la historia de Dios con los hombres». Ya ha dejado en claro que el filósofo parte de la pregunta del hombre por Dios y que el teólogo parte de la pregunta de Dios al hombre, mientras uno hace metafísica y eleva a conceptos experiencias, situaciones y esperanzas, el otro narra una historia para comprender el encuentro de Dios con el hombre. Obediencia (acogida de la iniciativa) y experiencia (fe hecha fermento) son los dos polos que sustentan la fe cristiana.

El deseo humano de Dios debe ser purificado, negado y convertido para que no se convierta en una refracción de nuestra indigencia, sino en una presencia de Dios como don y límite absoluto. En el cristianismo la filosofía será siempre la compañera de destino y el aguijón crítico de la teología.

El hombre no es que tenga una pregunta sobre Dios, es que es constitutivamente una pregunta por él. $\mathrm{Y}$ es aquí donde reaparece nuestro tema: «Es primero la idea del Infinito que la de lo finito, del inmortal que del mortal, del creador que de la criatura ${ }^{15}$, lo dicho que se aclara en la nota al pie: «Esta convicción es la que fundamenta la validez específica del argumento ontológico y explica la razón de su permanente reaparición, desde san Anselmo y Descartes a Hegel y Pannenberg...» ${ }^{16}$.

15 O. González de Cardedal, El quehacer de la teología, pp. 167-168.

16 O. González de Cardedal, El quehacer de la teología..., Idem, nota 12. 
Pero además de esta «fe filosófica», la teología cristiana nace de la «fe histórica»; el logos en la cruz es a la vez la cruz de la filosofía y la luz de la teología. Los dos rasgos característicos del Dios cristiano son la historicidad y la reciprocidad. La alianza es la forma fundamental que determina la existencia del pueblo y el comportamiento de Dios. La historia se convierte en ese misterioso tejido de propuestas de Dios y decisiones del hombre, que se afectan mutuamente. En este marco se inscriben la oración filial y la profecía esperanzada, la memoria y el amor. Si bien el modelo que propone en este trayecto es Agustín de Hipona, podría ser cualquiera de los autores monásticos, en oposición a la teología que pasa de la narración al sistema cuyo ejemplo es Tomás de Aquino.

La palabra primera es siempre la de Dios (Biblia e historia de la salvación), la segunda la del teólogo. La palabra primera se configura en torno a cuatro categorías claves en el Antiguo Testamento: elección, alianza, promesa y creación, para revelarnos a Dios, y en el Nuevo Testamento, nos manifiesta la persona de Jesucristo, lo que posibilita una doble lectura de la persona y del texto, basada en la doble proexistencia de Jesús. El teólogo siempre habla de Cristo, desde Cristo y sobre Cristo, que revela-entrega al Padre en el Espíritu, en su cuádruple legado: evangelio y eucaristía, Espíritu y apóstol, que se nos dan en la Iglesia (tradición, escritura, magisterio y teología).

A la verdadera teología le es esencial el pasar: de comprobar hechos a interpretar sentido; de descubrir sentido humano a reconocer revelación divina; de la historia a la Trascendencia; del hecho particular a la verdad universal; del fragmento a la totalidad; del relato al sistema; del contexto al contenido; de lo que apela a la experiencia a lo que lo hace a la razón; de la letra propia de la cultura al espíritu que une a todos los hombres, de la historia a la metafísica.

Así como el capítulo anterior se abría con una cita de uno de los teólogos monásticos este también se cierra con la referencia a otro: «San Anselmo enuncia el contenido-compromiso de la teología en sentido estricto como "Exemplum meditandi de ratione fidei = Monologio" "Fides quaerens intellectum" = Proslogio), como un pensar sobre la fe desde dentro de ella y correspondiendo a su lógica propia; por tanto como un creer que necesita comprender mejor para mejor amar y alabar con más ardor la sabiduría divina que todo lo ha hecho por razones necesarias, es decir que son la expresión del orden, belleza y justicia que rige el hacer divino y caracteriza 
sus obras. La teología no tiene como misión esencial deducir conclusiones de textos bíblicos o magisteriales sino ante todo penetrar en el contenido mismo del Misterio y en la lógica interna de la fe» ${ }^{17}$.

\section{IV}

En el «Lugar de la teología y los lugares teológicos» partiendo de la relación dialéctica entre los tres niveles semánticos de lugar, el emplazamiento confiere una misión y esta a su vez recrea, extiende o profundiza su propio emplazamiento, se analizan los tres lugares: exterior o enclave, interior o quehacer e interno o actitud del teólogo.

La Palabra, los testigos, la comunidad y el Espíritu son las condiciones de posibilidad de la teología y estas se han ido dando epocalmente de manera diversa: «A la luz de la historia tres han sido los lugares privilegiados en los que institucionalmente la teología ha nacido y se ha ejercitado. El primero ha sido la liturgia, el templo y el monasterio para mejor acoger, asimilar y pensar las realidades salvíficas, que se celebran, de las que se vive y a las que se ama. En este contexto se pretende entender más para mejor amar. Recuérdese el Proslogion, el Monologion, el Cur Deus homo, y las Orationes de san Anselmo. La adhesión creyente, la celebración y vivencia de la realidad creída desencadenan la luz y la intelección» ${ }^{18}$.

Los otros dos lugares como ya vimos han sido la universidad y la plaza pública. La teología cristiana no puede prescindir nunca de ninguno de estos tres ámbitos de realización, primero porque son el fondo donde se gesta la propia vida del teólogo, donde se instaura coherencia con la complejidad de su existencia y finalmente porque son los ámbitos fundamentales en los que debe cumplir su misión de anuncio y testimonio, de acreditación y apología.

El desde dónde originante de la teología coincide con el hacia dónde consumador. Teología en su originario sentido significa alabanza, eucaristía, divina liturgia y se ejercía en la admiración agradecida, como nos lo recuerda el autor en referencia a un célebre estudio de Leclercq sobre Jean de Fecamp ${ }^{19}$, aunque luego pasara a convertirse en su contrario:

\footnotetext{
17 O. González de Cardedal, El quehacer de la teología..., 230-231.

18 O. González de Cardedal, El quehacer de la teología..., 244. En cita hace referencia a Corbin.

19 O. González de Cardedal, El quehacer de la teología..., 254.
} 
autoafirmación del hombre frente a Dios, expresión del pecado original y de la idolatría, como señala Chenu.

La teología tiene tres movimientos internos que nunca puede obviar: pregunta del hombre, Palabra de Dios al hombre y respuesta del hombre a Dios. Este diálogo ha nacido en diversos contextos, que dan razón del pluralismo teológico al servicio del único evangelio de Jesús y de la fe común de los cristianos. De los diez lugare ${ }^{20}$ que enumera el quinto es el que nos interesa: "Los monasterios como "schola dominici servitti", en los que se copian los manuscritos de la cultura clásica y se lee e interpreta la Sagrada Escritura en una lectio divina, que es exégesis espiritual, preparación para la divina liturgia y ayuda para la ascensión del monje hasta la contemplación de Dios» ${ }^{21}$.

La teología encontrará siempre su lugar interior donde encuentre su objeto: Historia de la salvación y Liturgia, Sagrada Escritura y Comunidad, Espíritu de Jesús, Hombre que pregunta y situación histórica, que sin dudar están presentes en la teología monástica. Lugar interior y emplazamiento exterior son igualmente esenciales para la teología.

Cada lugar lleva consigo su lenguaje, sus protagonistas, su género literario, su determinado objeto, su finalidad espiritual, su predilección pastoral, sus consecuencias sociales, sus presupuestos y apoyos económicos, su comprensión de la existencia cristiana, sus mediaciones: "Cada lugar de la teología determina un campo semántico para las palabras utilizadas. Así la teología monástica tiene en la Biblia y en la Liturgia el humus en que se arraiga y el universo patrístico de los símbolos y experiencias desde donde hay que entender cada una de las alusiones verbales o conceptos insinuados ${ }^{22}$. En la nota al pie remite nuevamente a Leclercq de quien es deudor de la distinción, no oposición, entre las dos teologías medievales, y continúa: «De estas dos teologías, la escolástica tiende a la ciencia (explicación, comprensión...), mientras que la monástica tiende principalmente a la sabiduría (conocimiento amoroso, conversión de costumbres...)» ${ }^{23}$.

20 Esta concepción es diversa de la ya clásica de Melchor Cano y de la nueva aportada por la teología de la liberación.

21 O. González de Cardedal, El quehacer de la teología..., 258.

22 O. González de Cardedal, El quehacer de la teología..., 263.

23 O. González de Cardedal, El quehacer de la teología..., 263. 
Cada lugar orienta hacia unas lecturas y autoridades, así por ejemplo, en la Universidad de Salamanca, la diversidad de órdenes religiosas con sus respectivos «teólogos patricios», en el caso de los benedictinos es san Anselmo ${ }^{24}$.

Este capítulo es sin duda alguna el más rico en referencias y precisiones para nuestra temática.

\section{V}

«El conocimiento teológico: Objeto y método». En el interjuego historia, teología y metafísica la segunda reclama algo más que comprobar hechos e interpretar textos; pasa de los hechos particulares al ser universal, del cómo al qué, si bien nunca puede alcanzar estos contenidos dogmáticos sin tomar absolutamente en serio los textos bíblicos, ni llegar a la universalidad humana sin pasar por la particularidad judaica y a la esencia sin pasar por los acontecimientos. La teología no es metafísica, pero no puede vivir sin ella. La verdad nos es dada en el lenguaje y reclama método, pero no es ni el lenguaje ni el método, por eso el teólogo debe trascenderlos. De igual manera la historia es el lugar, no el criterio de la verdad.

El conocimiento teológico está constituido por un objeto (Dios como aparece en la revelación: Dios trinitario, Cristo cabeza) que ha variado a lo largo de la historia, un sujeto (el creyente, una razón iluminada por la $\mathrm{fe}$, el cómo, el camino a la meta) propuesto diversamente desde los $\mathrm{Pa}$ dres hasta el Vaticano II) y unas mediaciones específicas posibilitadoras (Tradición y Sagrada Escritura). La revelación es el principio objetivo y la fe el principio subjetivo del conocimiento teológico.

Las tareas que todo método teológico debe cumplir son cuatro: auditus fidei (audición), intellectus fidei (intelección), praxis fidei (realización), testimonium fidei (proposición). En la segunda tarea la referencia al lema anselmiano es ciertamente inevitable ${ }^{25}$, así como la alusión a la liturgia y la oración en la cuarta. Estas tareas se convierten en exigencias: histórica, crítica, hermenéutica, práxica, pragmática o apologética.

El teólogo no puede demostrar la necesidad de su objeto que es la revelación, porque esta es libre, pero una vez que esta ha tenido lugar sí

24 Cf. O. González de Cardedal, El quehacer de la teología..., 264.

25 Cf. O. González de Cardedal, El quehacer de la teología..., 314. 
puede y debe mostrar el orden de la belleza y la verdad propias de Dios. "En este sentido la teología habló de "razones necesarias", sin ingenuidad alguna y sin la pretensión prometeica de demostrar nada en Dios» ${ }^{26}$. No se puede pensar y decir «razones necesarias» sin asociarlas espontáneamente con el abad de Bec.

VI

El capítulo «Técnica, alma y carisma» no tiene referencias explícitas a nuestro tema, pero sí implícitas al hablar de la teología como una sabiduría, además de técnica, arte y ciencia, y más aún al tratar del alma del teólogo, es decir sus actitudes y disposiciones: interioridad (silencio, soledad, atención, vigilancia), empatía (pasión, compasión, confianza, connaturalidad) y oración (santidad), que son esencialmente monásticas. El modelo como hemos dicho antes es Agustín, pero podría ser cualquiera de los pensadores monásticos.

Si bien el carisma de teólogo tiene cierta analogía con el del científico, el filósofo y el poeta. Se diferencia del primero en que su discurso es soteriológico no cosmológico y su lenguaje es el de la confesión, no el de la explicación; del segundo porque habla de el Santo (Misterio Trinitario y Mística: divinización del hombre) y no del Ser (filosofía: discurso ontológico, lenguaje de la comprensión). El poeta es en un sentido mucho más (creador) y en otro mucho menos que un teólogo (profeta, didáskalos, mistagogo) que dice (anánmesis, parénesis y prolepsis) la alabanza (doxología) divina, sintetizando el conocimiento (dimensión intelectiva) y el amor (dimensión afectiva) de Cristo en la Iglesia para los hombres. Como la teología monástica es teología del culto y la liturgia, esto se cumple en ella, porque como afirma san Gregorio y repite la escuela cisterciense: «amor ipse notitia».

\section{VII}

En el capítulo «Fundamentos, problemas, tareas» la teología es presentada como un saber sobre la fe, a la vez que un saber desde la fe, un creer sabiendo, es decir, ciencia de la fe en sentido objetivo (fides quae) de hechos, dogmas y misterios (contenidos de la revelación como realidad en relación). Y aquí reaparece nuestra temática: «La iglesia inclina en unas

26 O. GonzÁlez de Cardedal, El quehacer de la teología..., 319. 
épocas y por unos sectores de ella a la adoración y a la alabanza del Misterio indiferenciado en el silencio (mística, monaquismo, liturgia, misterios, Oriente), en otros, por el contrario, a la racionalización y sistematización de la fe (intelectualismo racionalista, teología universitaria, dogmas, Occidente). En el primer caso la teología es comprendida sobre todo como inteligencia de la fe y fija la mirada en el "sujeto" de la teología que es Dios mismo, realidad personal inderivable, mientras que en el segundo orienta la atención a lo que él nos ha revelado y a sus implicaciones, es decir a la deducción de conclusiones de los principios o hechos fundamentales. En el primer caso la actitud requerida es la "especulativa" o contemplativa mientras que en la segunda es la "discursiva" ... $»^{27}$.

Pero la teología también es ciencia desde el creer del hombre (fides $q u a$, principio sobrenatural de iluminación y de connaturalización con Dios), desde la conversión (religiosa, moral, intelectual) y la existencia nueva que la fe (don de Dios y habitud-habito del hombre) trae consigo. La fe es lumen, instinctus, appetitus, con una triple función: purificadora, iluminadora, conformadora. Quien ha recibido la fe, se ha dejado configurar por Cristo y es guiado por el Espíritu, en la Iglesia (sujeto de la fe, la celebración, la predicación y la teología) como lugar de los dones salvíficos (revelación, Espíritu, sacramentos), ese tiene las condiciones de posibilidad para ser teólogo. Sin fe ni Iglesia no hay teología.

\section{VIII}

«El lenguaje y el sistema de la teología». Si bien el problema del lenguaje teológico (pasaje del conocer a Dios al hablar sobre Dios) no es nuevo, ya en el Pseudo Dionisio y Santo Tomás encontramos repuestas, es una de las cuestiones fundamentales desde el giro lingüístico, el neopositivismo, el estructuralismo y la posmodernidad.

La respuesta clásica al problema pasaba por la noción de analogía y la lógica de la participación. Desde el Pseudo Dionisio se habla de teología discursiva-positiva (causalidad), simbólica-negativa (ablación) y mística-apofática (exceso). En este último marco se desarrolla la teología monástica. La respuesta moderna propone la dialéctica como superación de la analogía. La primera sería una teología anabática o ascendente

27 O. González de Cardedal, El quehacer de la teología..., 383. 
(analogia entis) y la segunda catabática o descendente (analogia fidei), theologia crucis.

El lenguaje teológico se articula desde la Escritura, en diálogo con el exegeta, como un lenguaje performativo (confesión) que a lo largo de la historia se va expresando en contextos diversos, en géneros literarios diversificados, pasando de la lógica de la narración propia del lenguaje bíblico a la lógica del sistema. El método, el lenguaje y el sistema con la racionalidad del discurso lógico, lenguaje coherente y revivible y propuestas universales son condiciones de posibilidad necesarias pero no suficientes de la teología (doctrina cristiana o totalidad de lo cristiano en los Padres, teología dogmática o la normatividad de la revelación en las summas y manuales, teología sistemática o la organización -correlacióninteligibilidad de la totalidad), solo sirven para la verdad del camino.

\section{IX}

"La libertad de la teología y la libertad del teólogo». Después de un primer capítulo donde se plantea la relación teología-libertad, especialmente desde las tesis de E. Jüngel, el segundo se detiene en la relación teología-autoridad, en la clave de una triple eclesialidad: teórico-científica (origen), orgánico-funcional (fin); histórico-pragmática (eficiencia). En este momento nuestro autor trae a colación la crisis de Guardini estudiante de teología ante sus profesores modernistas y liberales que lo llevó a preguntarse por la especificidad del conocimiento teológico frente a las demás áreas del saber: «Aquí sitúa su descubrimiento de la liturgia, de la Iglesia, de san Anselmo y de la verdadera naturaleza de la teología ${ }^{28}$, que tiene en la revelación su hecho originante, en la iglesia su portadora y en el dogma su ordenación del pensamiento.

Aquí se diferencian las funciones del obispo-pastor y del teólogodoctor, que deberían complementarse-integrarse más allá de los conflictos-tensiones (teología sin autoridad y autoridad sin teología), desde coordenadas cristológicas y pneumatológicas. El apartado «Teología y ciencia» viene a sintetizar lo dicho, enmarcando la libertad y la autoridad en la Iglesia, porque la libertad (de y para) de la teología es directamente proporcional a su eclesialidad y su eclesialidad a su libertad. Es así que la teología por ser tal se debe a una doble lógica: la de la Iglesia

28 O. González de Cardedal, El quehacer de la teología..., 494. 
(autoridad) y la de la ciencia (libertad), ya que su objetivo primero es mostrar la verdad del cristianismo, con sus respectivas pretensiones de objetividad y universalidad, fecundidad y definitividad, lo que trae aparejadas amenazas externas (filosofía), internas (suplantación-reducción) y personales (tentaciones del teólogo).

\section{$\mathrm{X}$}

En el capítulo "La teología en la situación espiritual del siglo XX» encontramos tres referencias a nuestra temática.

Al hablar del nuevo punto de partida retoma un hecho al que ya se ha referido en dos oportunidades, cuando la teología cristiana estaba herida de muerte por el liberalismo y el modernismo, basados uno solo en hechos positivos o solo en vivencias subjetivas de la fe el otro: «En esos momentos hay un retorno a san Anselmo recuperando su fórmula: "fides quaerens intellectum". A él le dedica Barth un libro que es como los prolegómenos o fundamentación crítica de toda su teología dogmática, y otro, Romano Guardini, en que bajo el título "Credo ut intelligam" estudia la dependencia del conocimiento teológico de la fe ${ }^{29}$.

Frente al positivismo bíblico, el liberalismo doctrinal y el dogmatismo eclesiástico la figura-estilo de un teólogo monástico aportó una respuesta fecunda, recordando que la teología tiene un objeto propio (revelación), un principio propio (fe) y un sujeto propio (Iglesia). Historiadamente primero fue la Iglesia, luego la Biblia y después la Teología. La racionalidad de la teología implica historia (pasado), comunidad, transmisión, interpretación (presente) y orientación (futuro).

La teología es entendida como una inevitable ejercitación metafísica, afirmación que se problematiza en el apartado siguiente "Gloria y crisis del pensamiento» donde la diversidad de ejercitaciones de la razón y sus respectivas imágenes de mundo postulan la crisis de la metafísica en el pensamiento débil postmoderno, con un desfondamiento que llega a postular la ausencia del espectador, más que la negación de su existencia. Ante este descrédito de la razón una de las urgencias es su salvación, que solo será posible desde un renacimiento del ser y del hombre por la palabra resanada (sabiduría-conciencia-eternidad). Aquí la teología

29 O. GonzÁlez de CARdedal, El quehacer de la teología..., 543-544. 
monástica puede aportar algo desde la tradición, pero que deberá ser reformulado por tratarse de un nuevo contexto.

El intento de los teólogos posconciliares es plantear una teología orientada a luz de las fuentes (Biblia, Liturgia y Tradición), elaborada a la luz de la antropología (trascendental, fenomenológica y relacional), en diálogo con las nuevas misiones y situaciones. Todo esto significa una nueva ejercitación de la razón después del Vaticano II, con un nuevo método (punto de partida: dolores y gozos del hombre, problemas históricos y preguntas concretas), nuevos lugares de inserción del teólogo entendidos en este sentido como lugares teológicos. Este tema ya ha sido considerado anteriormente y en el que reaparece muestra preocupación: «En el tiempo del posconcilio los lugares de la teología siguen siendo los tres clásicos: la contemplación en el monasterio, la reflexión en la universidad y la acción en la vida pública. En el diálogo y en la adoración, los creyentes, tras haberla oído previamente (lectio divina), han meditado la palabra de Dios y la han actualizado sacramentalmente en la liturgia y testimonialmente en la vida. A partir de esa auditio, ruminatio, contemplatio y dilectio ha surgido una teología monástica, que no solo se ha realizado físicamente en los monasterios, sino en todos aquellos grupos y por aquellas personas que ha vivido tales actitudes. La teología nacía de la oración y servía para la edificación y la predicación» ${ }^{30}$.

Y unos renglones más adelante realiza una nueva síntesis: «Las tres son acentuaciones de una manera nueva de pensar el quehacer teológico, su objeto y su método. La teología monástica sirve, ante todo, a la caridad; intellectus caritatis: ut Deum diligamus et boni fiamus; la teología académica sirve a la fe-intellectus fidei: ut Deum et hominem cognoscamus-; la teología política sirve a la esperanza en sus explicitaciones mediadoras de justicia y solidaridad intrahistórica -intellectus spei: ut mundum novum anticipemus $\leadsto$. ${ }^{31}$. Tres formas de vivenciar las virtudes teologales.

Pero la novedad del posconcilio también reside en una nueva inserción de la Iglesia en la sociedad, con nuevas experiencias y esperanzas históricas en un mundo secularizado, animada por los nuevos alientos del Espíritu (santo) y del espíritu (Zeitgeist de Hegel). Un ejemplo claro lo encontramos en la teología de la liberación con su aporte desde

30 O. González de Cardedal, El quehacer de la teología..., 580.

31 O. González de Cardedal, El quehacer de la teología..., 581. 
el Tercer Mundo, con su percepción histórica convulsiva (el hecho de los pobres en el mundo), su dialogante privilegiado (idólatra histórico), su método de pensamiento (praxis histórica transformadora), su nueva forma de quehacer teológico (mediación social-científica, hermenéutica y práctica) como retroapropiación del origen cristiano a partir de estas experiencias históricas, recreando una iglesia con una espiritualidad que une contemplación y arriesgo. Esto es un ejemplo de cómo: «la teología tendrá ya su morada natural no solo en el monasterio por la contemplación y en la universidad por la reflexión crítica, sino en el espacio de la acción pública por la creación de la justicia y de la esperanza» ${ }^{32}$. Anotemos por nuestra cuenta que este último aspecto no estuvo tampoco ausente en la teología monástica, tanto Anselmo como Bernardo fueron un ejemplo de acción política, uno que en la lucha de las investiduras fue el defensor de la libertad de la Iglesia, y el otro fue el árbitro pacificador de la Europa de su tiempo, y hay que decirlo también, con su participación no muy feliz en la cruzada.

Antes de continuar es bueno recordar que: «En fases anteriores, como la Edad Media cuando la Iglesia y la sociedad vivían en ósmosis formando una única cristiandad y donde la realidad de Dios tenía evidencia y vivencia sociales, el teólogo podía concentrarse en la propuesta de los contenidos de la revelación positiva, sin necesidad de detenerse en los presupuestos racionales de la fe y de la Iglesia, por ser socialmente reconocidos y no ser puestos en cuestión» ${ }^{33}$. El autor señala el vínculo teología-contexto, teología-cultura; desde esta perspectiva, la teología monástica puede resultar extemporánea si se la considera solo en su via expositionis, pero si la miramos desde su via inventionis podríamos hasta considerarla extemporánea en el segundo sentido.

XI

Nos encontramos ahora ante un hecho bastante curioso, al tratar de las "Figuras de la teología y del teólogo en la historia», donde a la luz de las leyes normativas de la teología: principios, método, lenguaje y criterios, se considera la biografía para descifrar la raíz y las articulaciones del pensamiento de cuatro teólogos para saber qué es la teología, ya que la

32 O. González de Cardedal, El quehacer de la teología..., 596.

33 O. González de Cardedal, El quehacer de la teología..., 582. 
razón teológica tiene su historia, sus épocas en las que se encuentra con unos problemas, debe responder a unas preguntas y elegir unos métodos (el judeocristianismo con su diálogo con los modelos judíos, la patrística en su diálogo con el pensamiento griego y la herejía, la edad media bajo el régimen de su lógica interna y de la lógica de la universidad, el siglo XVI con su relación con el nominalismo, siglos XVII-XVIII en su relación con el racionalismo de la modernidad, el siglo XIX con el idealismo, siglo XX en diálogo con la existencia creyente, y el siglo XXI con la posmoderndidad, el diálogo ecuménico, la inculturación, la diversidad). En cada etapa se generan unas instituciones y dentro de ellas el respectivo tipo de teólogo, que se comprende solo desde su contexto, eclesial, social y cultural.

Lo curioso del caso es que aquí no aparece mencionado nuestro tema en los dos lugares lógicamente posibles, en la edad media como alteridad de la teología universitaria, pensamos que esta omisión se debe a la proximidad-continuidad con la patrística donde los teólogos eran a la vez obispos, monjes y exegetas ${ }^{34}$, o en la época de su recuperación, el siglo XX, con Leclercq, lo apretada de la síntesis que realiza no aborda todos los influjos de la nouvelle theologie, ni todos los discípulos de Chenu.

Lo mismo ocurre cuando trata las áreas de la teología: positiva (exégesis, patrística e historia de la Iglesia: misión, espiritualidad y dogma), sistemática (dogmática, fundamental, moral), práctica (liturgia, pastoral, homilética, catequética), comprendemos la ausencia de nuestro tema porque la globalidad del quehacer teológico monástico no distinguía entre modus vivendi, modus orandi, modus credendi atque cogitandi ${ }^{35}$. Intentar clasificarlo hubiera sido hacerle violencia.

Luego se aboca a las personalidades singulares: Agustín, Tomás, Kierkegaard, Balthasar. Es llamativo, pero en realidad no tanto, que los cuatro a su modo, en cada época histórica, hayan tenido algo que ver con los monjes. Agustín con lo que el autor llama «proyecto de vida filosófica monásticamente vivido» ${ }^{36}$; Tomás «hijo espiritual de san Benito» ${ }^{37}$, Kierkegaard, que sería algo así, perdón por el atrevimiento, como un monje

\footnotetext{
34 Cf. O. González de Cardedal, El quehacer de la teología..., 617.

35 Cf. O. González de Cardedal, El quehacer de la teología..., 639.

36 O. González de Cardedal, El quehacer de la teología..., 644.

37 O. González de Cardedal, El quehacer de la teología..., 645.
} 
luterano, creo que habría sonreído con la paradoja; y von Balthasar, a quien debemos algunas de las interpretaciones más bellas en nuestra época de Anselmo y Bernardo.

Luego plantea nuevos criterios de diferenciación: medios y formas literarias de expresión (imágenes, metáforas, ideas y sistema), formas de escritura (intención narrativa, edificante apologética o sistemática), contenidos o métodos, estilo de pensamiento (pensadores, escritores y sistemáticos), y a la luz de las tipificaciones anteriores comprueba que hay teólogos totales y parciales, nosotros tampoco sabríamos aplicar estos criterios de diferenciación y catalogación a nuestros autores, porque no hay lugares precisos para realizar los cortes.

Pero es significativo que al hablar del teólogo moderno (posmoderno) es cuando aparece la última referencia a un teólogo monástico medieval ante la pregunta siempre clave, que hace eco a la nuestra: «¿Adónde debe mirar... el teólogo? ¿A qué debe mirar con mayor atención: a la memoria o a la esperanza? De la teología hay que decir lo que san Bernardo decía de la Iglesia: "ante et retro oculata" (Tiene ojos por delante y por detrás para mirar al pasado y al porvenir)» ${ }^{38}$, solo así se puede ser un teólogo verdadero, no solo de profesión, que puede vivir y entender el presente.

XII

«La existencia teológica. Quién y cómo es un teólogo». La teología más que un quehacer ocasional es un ser permanente que afecta a la vida entera y a sus ejercitaciones. Hasta ahora nuestro autor había planteado su acercamiento a la teología desde la objetividad, en cambio en este capítulo habla de la subjetividad o de la personalización de la teología, porque si bien el teólogo nunca habla de sí mismo, siempre lo hace desde sí mismo.

El santo apela a su testimonium interius, el obispo a su potestas iuridi$c a$, y el teólogo a su auctoritas doctrinalis, en la Iglesia y desde los signos de los tiempos. Esto presupone tres actitudes personales, radicales: veracidad (no solo sinceridad, sino también coherencia), libertad (como emancipación y servicio) y docilidad, unidas a una conciencia lúcida de su diferencia e identidad (intencionalidad teológica) y a la asunción gozosa de su misión.

38 O. GonzÁlez de Cardedal, El quehacer de la teología..., 659. 
Llegamos así al final de un recorrido que a veces fue lineal y otras circular a una reflexión sobre la lógica del cristianismo y la lógica de la teología, porque la lógica de la teología debe nacer y corresponder a la lógica del cristianismo (aspecto objetivo) y a la lógica de la vida cristiana (aspecto subjetivo). El cristianismo es contenido (Evangelio, credo, dogma), es forma o estructura (comunidad, institución, Iglesia), es palabra (celebración, predicación, teología), y cada uno de estos tres elementos repercute en el otro. No hay contenido al margen de una forma y de una interpretación; mientras que la forma y la interpretación están determinadas por el contenido, por eso la teología tiene cuatro principios: histórico (dogmático), encarnativo (Cristocentrismo), sacramental (Misterio) y escatológico (esperanza).

Creemos que todo esto se cumplió, ciertamente mutatis mutandis, en el quehacer de la teología monástica del pasado y debe actualizarse en la del presente, porque "quehacer dice "menester" en el doble sentido de profesión y de necesidad u obligación por cumplir, seriedad y urgencia de la teología, tanto para la Iglesia como para la sociedad, si no quiere perder de su horizonte realidades esenciales y sucumbir a tentaciones mortales» ${ }^{39}$.

S. S. Benedicto XVI en su Discurso en la entrega del "Premio Ratzingen», el 30 de junio de 2011, refiriéndose a nuestro autor dijo: «En su larga vida de estudioso el profesor González ha tratado todos los grandes temas de la teología, y eso no simplemente reflexionando y hablando de ella desde un escritorio, sino también confrontándose siempre con el drama de nuestro tiempo, viviendo y también sufriendo de una forma muy personal las grandes cuestiones de la fe y así las cuestiones del hombre. De este modo la palabra de la fe no es algo del pasado; en sus obras se hace verdaderamente contemporánea a nosotros» ${ }^{40}$.

Esto enmarca adecuadamente la respuesta-apuesta-propuesta que encontramos en El quehacer de la teología: La teología monástica es extemporánea en el segundo sentido del término, porque es postemporánea, y por eso nuestro quehacer-menester es hacerla contemporánea. Es lo señalado a continuación por el Papa al dirigirse, en el citado discurso, al

39 O. González de Cardedal, El quehacer de la teología..., 16.

40 Benedicto XVI, «Discurso durante la entrega del Premio Ratzinger en su primera edición», en L'Osservatore Romano XLIII, 27 (2011), 5. 


\begin{abstract}
Abad cisterciense Maximilian Heim expresando el deseo de que: «pueda desarrollar... en nuestro tiempo, la teología monástica, que siempre ha acompañado a la universitaria, formando con ella el conjunto de la teología occidental» ${ }^{41}$.
\end{abstract}

41 Idem. El papa ha dedicado varias catequesis a la teología monástica y sus principales representantes en 2009 y 2010, al igual que algunos discursos, por caso el dirigido al mundo de la Cultura en el Collége des Bernardins en 2008; preocupación presente ya desde su época de Prefecto de la Congregación para la Doctrina de la Fe: «...merece atención un aporte de G. Alberigo publicado hace poco, sobre el desarrollo y las características de la teología como ciencia. Alberigo muestra cómo, en las postrimerías del siglo XII la teología se traslada de sus sitios anteriores -la casa episcopal, el monasterio y el convento de clérigos regulares- al ámbito nuevo y eclesiásticamente neutral de la universidad, y así cambia fundamentalmente su fisonomía, tanto institucional como espiritual y científica. Alberigo muestra también la inevitabilidad de este proceso ante el agotamiento de la teología patrística y monástica. Destaca el provecho que esto implicó para la teología y que consistió, no en último término, en la "mayor libertad de la investigación teológica". Pero el destacado historiador muestra también el reverso de esta "dislocación" de la doctrina (y de la investigación), que las aparta de los “centros eclesiales más vitales”, la diócesis y el monasterio, y con ello significó un salir del contexto pastoral y espiritual de las realidades de la Iglesia local. La orientación hacia un estatuto científico de la teología introdujo un proceso de separación, tendencia respecto de la vida eclesial; se genera "un hiato (cada vez más fuerte) entre la comunidad cristiana y la institución eclesiástica, por un lado, y la corporación de los teólogos, por el otro. El hecho de que la universidad se convirtiera en el nuevo lugar de investigación y de la enseñanza teológica empobreció sin duda su dinámica eclesial y separó a la teología de su contacto vital con las experiencias espirituales"...» (J. RATZINGER, "Acerca de la Instrucción sobre la vocación eclesial del teólogo» en Naturaleza y Misión de la Teología (Agape, Bs. As. 2007), 127-128). 
Resumen: Desde El quehacer de la teología, obra del teólogo español Olegario González de Cardedal, se formula y responde la cuestión: ¿la teología monástica es, con respecto a nuestro propio tiempo histórico, extemporánea? "Hay autores que son extemporáneos respecto de su tiempo, unos porque resultan arcaicos, es decir reflejan una fase de la conciencia humana ya agotada o superada, otros, en cambio son extemporáneos, porque hablan desde un horizonte y percepción nueva del cristianismo para los cuales todavía no hay ojos ni oídos». Los primeros son propiamente extemporáneos y los segundos postemporáneos. La teología monástica es extemporánea en el segundo sentido y por eso nuestro quehacer-menester es hacerla contemporánea.

Palabras clave: Teología monástica, teología contemporánea, quehacer teológico, teología fundamental.

Abstract: Based on El quehacer de la teologia (The theological task), the work of Spanish theologian Olegario González de Cardenal, this article formulates and responds to the question: with respect to our historical time, is monastic theology extemporaneous? "Some authors are extemporaneous with respect to their time, some because they are archaic, that is, they reflect a phase of human consciousness that has been exhausted or overcome, and others because they speak from a new horizon and perception of Christianity for which there are not yet eyes or ears." The former are properly extemporaneous, while the latter are post-temporaneous. Monastic theology is extemporaneous in the second sense, and therefore our taskneed is to make it contemporary.

Keywords: Monastic theology, contemporary theology, theological task, fundamental theology. 